\title{
El nuevo ciclo de movilización mapuche en Chile: la emergencia de la CAM y el proyecto autonomista para una región plurinacional $^{1}$
}

\section{The new cycle of mapuche mobilization in Chile: the emergence of the CAM and the project for a plurinational autonomy region}

\section{José Marimán ${ }^{2}$ \\ Centro de Estudios Mapuche Rüntun, Santiago (Chile)}

Esteban Valenzuela ${ }^{3}$

Francisco Cortés ${ }^{4}$

Universidad Alberto Hurtado, Santiago (Chile)

Recibido: 25-06-15

Aprobado: 14-07-15

\section{Resumen}

El artículo pone en contexto histórico el nuevo ciclo de movilizaciones mapuches, que se ha intensificado en la última década. El movimiento mapuche es el principal movimiento en Chile a favor del poder territorial autónomo, que

\footnotetext{
${ }^{1}$ El artículo es parte del FONDECY N¹150684 "Movimientos Regionalistas y Transformaciones Políticas en Chile 2011-2016: Entre la cooptación y el poder autónomo".

2 (ppmariman@hotmail.com). Doctor en Ciencia Política de la U. Santiago de Compostela, Máster en Ciencia Política de la Universidad de Colorado e historiador de la Universidad de la Frontera (Temuco). Es director del Centro de Estudios Mapuche Rüntun y del Diplomado en política indígena de la UAH. Autor del libro Autodeterminación: Ideas politicas mapuche en el albor del siglo XXI. (2012, Santiago: LOM Ediciones.

${ }^{3}$ (evalenzuelavt@gmail.com). Doctor en Historia Contemporánea de la U. de Valencia. Máster en Desarrollo de la UW-Madison y Magíster en Ciencia Política de la P. U. Católica. Autor de Alegato Histórico Regionalista (1999, Santiago: SUR) y Descentralización Ya (2015, Santiago: RIL. Director del Magíster en Estudios Sociales y Políticos Latinoamericanos de la Universidad Alberto Hurtado Chile.

${ }^{4}$ (francisco.cortes.as@gmail.com). Licenciado en Ciencia Política de la Universidad Alberto Hurtado, ayudante de investigación del proyecto FONDECYT "Cooptación de Movimientos Regionalistas en tres coyunturas históricas de Chile". Realizó la tesis de licenciatura sobre $L a$ Coordinadora Arauco Malleco y la devolución de tierras a los mapuches. Labora en el área de desarrollo comunitario y ciudadanía de la I. Municipalidad de Maipú.
} 
resiste el sistema político presidencialista homogenizador, que es centralista y nacionalista. El artículo explica el despojo territorial a dicho pueblo/nación por el Estado chileno, y la lógica de minorización a la que se le ha mantenido en la nueva democracia, con políticas sectoriales pero sin autonomía y poder político. También se da cuenta de la complejidad del movimiento mapuche en la reivindicación de tierras a partir del año 1997, explicando la complejidad de la violencia en los territorios de La Araucanía, y la lucha con las empresas forestales. La principal propuesta de solución política del conflicto es aceptar la idea de región autónoma plurinacional, con un parlamento con cuotas indígenas, devolución de recursos, derecho indígena y recuperación de la lengua.

Palabras-clave: Mapuches, Chile, violencia, autonomía, regionalismo.

\begin{abstract}
The article explains in historic context the new cycle of Mapuche mobilizations that have been intensified in the last decade. This Mapuche movement is the principal movement in Chile for territorial autonomous power that resists a homogenizing presidential political system that is both centralized and nationalist. The article explains the dispossession of Mapuche territory by the Chilean state and the logic of minoritization that has been maintained in the new democracy with sectorial politics but no autonomy or political power. Next it will consider the complexity of the Mapuche movement and demands for the return of dispossessed lands beginning in the year 1997, explaining the complexity of the violence in the territory of the Araucania and the struggle against the forestry companies. The principal proposal for a political solution to the conflict is to accept the idea of a plurinational autonomous region, with a parliament with indigenous quotas, a process of devolution of resources, indigenous law and recovery of the mapuzungu language.
\end{abstract}

Key-words: Mapuches, Chile, violence, autonomy, regionalism. 


\title{
1. Introducción: Las raíces históricas de la fracasada dominación de una nación políticamente descentralizada, comunitaria e indómita
}

\author{
En La Araucanía no había capital, ni había un \\ emperador para secuestrarlo y colocar a todo un país \\ bajo dominación (Stephen Lewis [1994]).
}

Hay consenso en que el Estado Chileno comenzó a invadir el territorio mapuche en 1861, con el cual la Corona española había pactado el río BíoBío como su frontera (Tratados de Tapihue 1774, Negrete 1793 y 1803). Tanto gobiernos conservadores ${ }^{5}$ como liberales-federalistas ${ }^{6}$ reconocieron explícitamente a la nación mapuche y su macro territorio (Contreras, 2010). Correa y Mella (2010) documentaron la voracidad de los colonos y latifundistas chilenos entre fines del siglo XIX e inicios del XX para ocupar las tierras mapuches. Y una pléyade de investigaciones recientes muestra la negativa del Estado chileno a devolver poder y macro-territorios (Barrientos 2014, por ejemplo), más allá del período de reforma agraria de los Presidentes Eduardo Frei (1964-1970) y Salvador Allende (1970-1973), y el proceso de creación de la Corporación Nacional de Desarrollo Indígena (CONADI) ${ }^{7}$ bajo la primera presidencia pos-dictadura de la Concertación de Partidos por la Democracia: Patricio Aylwin, (1990-1994). El caso del intento más reciente de traspasar tierras a los indígenas, operado entre los años 1990 y el presente, mezquino en proporción a las necesidades y lento en términos de agilidad del proceso, ha terminado generando a partir de 1997 las movilizaciones mapuches del presente, bajo la forma de reclamaciones legales, tomas de terrenos y presunta quema de bosques. Decimos 'consenso' en torno a la usurpación ya que el gobierno del Presidente Ricardo Lagos (2000-2006) creó una comisión plural de historiadores que en octubre del año 2003 refrendaron esta idea en el Informe "Comisión de Verdad Histórica y Nuevo Trato".

En el ciclo de movilización indígena en América Latina, abierto en el contexto de la caída del socialismo en Europa y las celebraciones por parte de los Estados latinoamericanos del Quinto Centenario de la Conquista de América (1992), se produjeron las sublevaciones maya-zapatista en Chiapas (1994) y la activación quechua-aymara desde Ecuador a Bolivia (1997-2005).

\footnotetext{
5 Caso de Bernardo O'Higgins que gobernó como el primer Director Supremo de Chile entre 1817-1823.

${ }^{6}$ Caso de Ramón Freire que bajo la figura de Director Supremo y luego Presidente gobernó entre1823-1827 y firmó los Tratados de Tapihue 1825 y Tantauco 1826 con los mapuche.

La CONADI posee un fondo de recursos estatales destinado a comprar tierras a los pueblos indígenas que los reclaman, que se ha mostrado insuficiente e inoperante para dar salida a la demanda, generando desilusión e irritación hacia su gestión de parte de los pueblos indígenas.
} 
En movilizaciones donde la violencia social estuvo presente bajo la forma de recuperaciones de tierras y cuestionamiento al poder central (Estado) y represivo del sistema político chileno, los mapuche mostraron su vitalidad y persistencia como etno-nación. Dicho sistema no ha escuchado el reclamo de este pueblo/nación, tratando a los mapuches como campesinos pobres, con demandas sociales de superación de la pobreza pero no políticas o de autogobierno-autonomía (Chihuilaf 1999).

Dillehay (1990) coincide en la radical descentralización del poder de las comunidades mapuches, que las hace ingobernables tal como hacia 1550 las describiera Alonso de Ercilla y lo comprobara el jesuita Luis de Valdivia (Díaz, 2011), quien logró imponer períodos de treguas con su tesis de la "guerra defensiva"8 (Valenzuela 2013). Los mapuches nunca alcanzaron una organización de gobierno centralizado y lograron resistir dirigidos por jefes formales comunitarios (longkos y tokis) ${ }^{9}$ quienes se reunían a deliberar. Y agrega que la forma más jerarquizada de gobierno llegaba solo a una forma de unificación regional, a través de la gran congregación religiosa. Esta idea federal es híper desarrollada y hacia esas formas camina el mundo (Naim 2014), por lo cual son odiosos y torpes los epítetos de pueblo inferior hacia los mapuche, por la idea simplista de no tener mega ciudades como los aztecas o incas, que se derrumbaron en la conquista por su orden basado en la dominación de una elite oligárquica político-religiosa (Valenzuela 1999). Gleisner (1988) señala que ni los incas ni los españoles fueron exitosos al sur del Maule, porque era imposible la derrota y subordinación de los mapuches a una autoridad central. Lewis resume la clave mapuche:

En la Araucanía no había capital, ni había un emperador para secuestrarlo y colocar a todo un país bajo dominación. La organización de los araucanos era más débil; las diferentes tribus y clanes se miraban con desconfianza y a veces odio... Sólo bajo situaciones de guerra, los clanes y tribus se unificaban para pelear contra el enemigo común... Los españoles nunca tuvieron la alternativa de una figura institucional de alto poder, que hubiera facilitado el colapso de la resistencia araucana (1994:121).

Hay quienes sostienen que esas tendencias organizativas descentralizadas entre los mapuches han perdurado hasta hoy y que ellas no son compatibles con el formalismo centralista de la tradición legal chilena (dirigentes de organizaciones mapuches como la Coordinadora Arauco-Malleco - y cientistas sociales chilenos también- tienden a ver a los mapuches como no afectados por la relaciones establecidas con los hispano-europeos, sino como una cultura

\footnotetext{
${ }^{8}$ La guerra defensiva implicaba reconocimiento de territorio y potestades a los longkos (cabezas o caciques), como lo obrado por Bartolomé de las Casas en su postrero experimento de la Vera Paz con los mayas en Guatemala.

9 Toki es longko de longkos (cacique de caciques).
} 
continua en el tiempo). Otros, en cambio, creen que la situación colonial generada por la instalación de los hispano-europeos en Chile propició una relación entre mapuche y no mapuche que podríamos denominar situación colonial, que provocó cambios en las costumbres en ambos actores de la relación, de manera que no hay una cultura mapuche lineal sino varias, obedeciendo a las rupturas que las situaciones políticas crearon: una cultura mapuche prehispano-europea, una durante la situación colonial hispano-europea, otra con la creación del Estado chileno y el arreduccionamiento ${ }^{10}$. A esta última obedece la participación mapuche en el sistema-ordenamiento político estatonacional chileno, bajo la forma de movimiento etnogremial o etnosindical que apadrinó la presencia de mapuches en el parlamento chileno durante algunos momentos del siglo $\mathrm{XX}$, de la mano de instituciones estatonacionales como los partidos políticos chilenos (Marimán 2012).

De otra parte hay cientistas sociales chilenos que suelen decir que ya no queda ni cultura ni organización mapuche ${ }^{11}$ (Sergio Villalobos, 2000), y algunos presentan como evidencia del desapego el que ellos no votarían por candidatos de su pueblo. He aquí un nuevo disenso entre quienes intentan explicar la conducta electoral de los mapuches. Hay quienes postulan que no se entiende que al votar, el mapuche es colocado en un dominio de acción regido por otras racionalidades (Aucán Huicaman, 1992) ${ }^{12}$, y que hay ancestrales formas pasivas de resistencia a las estructuras de dominación, como el no inscribirse, no votar, anular el voto (las formas cotidianas de resistencia). Mientras otros sostienen que el voto mapuche es un voto útil, característico de minorías viviendo bajo situación de dominación/subordinación (Marimán 1990) o disperso a diferencia del voto étnico afroamericano en las elecciones estadounidenses. El voto de la población negra de EE.UU. (2008) fue Obama 97\%, mientras que los hispanos, más parecidos a los mapuche solo votaron por él en un 65\% (Cayuqueo 2006, Valdés 2007).

En la perspectiva de quienes sostienen que la cultura mapuche no ha sido modificada en el tiempo, cuando los gigantes hidroeléctricos les ofrecen a los mapuche-pehuenche compensaciones para abandonar sus territorios,

${ }^{10}$ Arreduccionamiento se le llama al proceso de expoliación territorial de los mapuche (10 millones de hectáreas en la Araucanía entre 1861-1883), y entrega de tierras en reducciones bajo la forma de un Título de Merced (1883-1927), a un promedio de 6,1 hás. por persona; mientras a colonos europeos se les repartieron las tierras expoliadas a un promedio de 500 hás. por persona, lo que originó la pobreza campesina mapuche presente.

${ }^{11}$ Sergio Villalobos es historiador y premio nacional de historia en Chile, con alta audiencia en la elites políticas ultra conservadoras de la sociedad estatonacional chilena, que ha opinado repetidas veces en periódicos nacionales y otros medios en el sentido de lo expresado, durante los últimos años.

12 Aucán Huicamán ha sido el líder histórico de la organización mapuche Consejo de Todas la Tierras (CTT), y sostenía esta idea en los primeros tiempos de dicha organización; aunque después cambió de opinión y se presentó en elecciones incluida la presidencial 2005. Hoy nuevamente está operando fuera del sistema, demandando autogobierno basado en la declaración ONU 2007 sobre los Derechos de los Pueblos Indígenas. 
el que discute con el alcalde o con el intendente no es un presidente ni una junta de vecinos. Entre los mapuche-pehuenche ${ }^{13}$, cada comunidad elige a un representante, todos los elegidos se reúnen en consejo y deliberan. Estructura descentralizada y de consejo, opuesta radicalmente a los dos conceptos pilares de nuestras instituciones: centralismo y presidencialismo. De hecho, la negativa de una decena de familias a permutas de terreno ha sido piedra de tope a dichos planes. Ellas representan a grupos que apelan a una soberanía sobre sus territorios. Las crecientes tomas de terrenos responden a un longko, el que se debe a la comunidad local y no a una organización central. Nuevamente un disenso aquí está dado por el hecho de que las formas de democracia y representación en comunidades pequeñas, sindicatos, clubes deportivos o lo que sea es mucho más directo y a mano alzada, que la que puede esperar un estado en términos de votaciones masivas. En el pueblo de Corcord en Massachusetts, USA, por ejemplo, se realiza un cabildo del pueblo para tomar decisiones, que viene desde tan atrás como los primeros tiempos de arribo de los colonos, y no tienen nada que ver con cultura indígena.

En lo que sí parecen estar de acuerdo todos es que hay una dimensión territorial en la representación mapuche y en sus reivindicaciones, que no se encontrarían en un sindicato o asociación profesional, luchando por mejoras salariales. Y esto último da pie para comentar que la violenta "pacificación de La Araucanía" (similar a la "Campaña del Desierto" del gobierno central argentino contra tehuelches y mapuches), tuvo un último intento de detenerla por una delegación de caciques, que viajaron a Santiago a reunirse con el presidente José Joaquín Pérez en 1862. En esa reunión se planteó la constitución de una provincia autónoma araucana, con departamentos cuyos gobernadores serían los mismos caciques (Leiva 1984). Se fracasó ante el desprecio centralista que se impuso en Chile en tres guerras civiles, en que federales/ liberales son derrotados (1830, 1851, 1859). Bengoa (1985), en su "Historia del Pueblo Mapuche", recuerda positivamente los diálogos y negociaciones con los representantes de la monarquía española, en especial los parlamentos de Negrete en 1793, las buenas relaciones con los grupos federales y sus alianzas en dichas guerras civiles. El Estado chileno, conducido desde la metrópolis, fue implacable y violento en su autoritarismo centralista.

Con posterioridad a 1930 y hasta 1972, las leyes indígenas, solo discuten la división de tierras, pero son muy pocas las tierras que se logran recuperar. Los conflictos en esta época se encapsulan en los Juzgados de Indios. Solo a partir de 1960, y hasta 1973, el movimiento mapuche reabre la reivindicación de tierras y procede por la vía de la ocupación de terrenos y por la expropiación

${ }^{13}$ Los mapuche-pewenche son un subgrupo de los mapuche que vive en las montañas de los andes (Región del Bíobío y Araucanía), e incluyen en su dieta la recolección del fruto denominado piñón (un tipo de nuez).

Araucaria. Revista Iberoamericana de Filosofía, Política y Humanidades, año 17, $\mathrm{n}^{\circ} 34$. Segundo semestre de 2015. Pp. 279-301. ISSN 1575-6823 e-ISSN 2340-2199 doi: 10.12795/araucaria.2015.i34.13 
por Ley de Reforma Agraria a recuperar tierras. (Correa et al. 2003, 2005).

Bajo la dictadura militar (1973-1989) hubo entrega de títulos individuales sobre las tierras en poder de los mapuche, acompañada de una amplia represión y desconocimiento de derechos comunitarios y macro territoriales. El primer decreto firmado por el General Pinochet en 1979 señalaba que, una vez dividida la comunidad, los ocupantes dejaban de considerarse mapuche (Decreto Ley 2.568). Esto fue rápidamente rechazado por los Centros Culturales Mapuche, primera organización mapuche emergida bajo la dictadura y en este contexto, que luego se transformaría en AD MAPU. De esta última organización se desprendieron varias otras, como Nehuen Mapu, Calfulicán y Lautaro Ñi Ayllarehue (Espinoza y Mella 2013). Al inicio de la transición a la democracia se mantienen las organizaciones nombradas, pero aparece el Consejo de Todas las Tierras (CTT), con un discurso autonomista de rescate y revalorización cultural, de reivindicación de tierras y una estrategia internacional de valoración de los derechos indígenas (Molina 2013).

\section{El origen de la Violencia en el Wallmapu: la irrupción de la CAM y las otras visiones}

Los sabotajes y ocupación de tierras usurpadas se han intensificado por los mapuches a partir del año 1997, sobre todo en la Región de la Araucanía y la provincia de Arauco, colindante por el noroeste con La Araucanía, y que pertenece a la región del Bío Bío (capital Concepción). Los mapuche llaman Wallmapu a su territorio histórico, reducido en el presente a la región de la Araucanía más zonas colindantes de las regiones Bío Bío por el norte y Los Ríos por el sur (mapa 1). En esta zona vive una parte importante de los mapuches, constituyendo el $30 \%$ de la población regional ${ }^{14}$. El resto se reparte en las regiones limítrofes y otras más lejanas, especialmente la Región Metropolitana. En ciudades importantes como Concepción (región del Bío Bío), Valparaíso ( $V^{a}$ Región de Chile) y Santiago (capital del país). En particular, en este último lugar viven medio millón de mapuches. La Araucanía posee varias comunas o municipios en que los mapuches son mayoría: Chol Chol, Ercilla, Puerto Saavedra, Currarehue, entre otros. Y en comunas colindantes de regiones vecinas también se da el mismo caso: Alto Bío-Bío, Tirúa (región del Bío Bío).

¿Qué explica que en algunas partes haya más violencia y en otras menos en las relaciones interétnicas o plurinacionales? Sin duda las explicaciones pueden ser variadas, pero en este caso las desigualdades sociales, económicas

\footnotetext{
${ }^{14}$ Proyecciones del CENSO 2012. El censo del 2012 en Chile se considera fallido. Arrojó una cifra de población mapuche del orden 1.800.000. Censos anteriores (1992 y 200) arrojaron cifras menores pero contradictorias todas entre ellas. En materia de contar población indígena los censos de Chile han mostrado ser bastante cuestionables.
} 
y los prejuicios raciales juegan un rol principal. Esas desigualdades permiten considerar a los individuos, sus grupos familiares, y su sociedad entera (étnica o nacional o etnonacional) como abusados por otro grupo nacional (la nación estatal): los chilenos. Y cuando estas lecturas-comprensiones son hechas en estos términos, las relaciones con el "otro" son asumidas como conflicto étnico o nacional (etnonacional). Entonces, las condiciones para respuestas comunitarias están dadas y los conflictos se agudizan. Por ejemplo, Ana María Oyarce, en un estudio CEPAL reciente (2012), nos habla de los problemas con el agua en la comuna de Ercilla, donde las plantaciones de pino han secado las napas subterráneas en propiedades mapuches, que hoy dependen de camiones aljibes municipales, para surtir un promedio de agua por habitante en las comunidades de la zona, que llega apenas a 4 litros (+/-), y que está muy por debajo de los estándares reconocidos por la Organización Mundial de la Salud (OMS): 7,5 litros diarios por persona. Las comunidades campesinas mapuche que sufren el flagelo de no contar con agua en Malleco (y en la Araucanía entera) ${ }^{15}$ atribuyen su carencia a los chilenos y sus compañías madereras (industria forestal). Y otros mapuches lejos de la situación se solidarizan con ellos (solidaridad étnica desde las ciudades), asumiendo su lucha como propia.

El movimiento mapuche se ha activado porque el Estado favorece las grandes empresas forestales, no devuelve las tierras usurpadas a las comunidades campesinas mapuche, no reconoce derechos políticos a los mapuche según las propias convenciones ONU que el Estado ha ratificado, y ha relegado a la Araucanía a seguir siendo la región de mayor pobreza del país. El cuadro anterior ha llevado a la explosión social-reivindicativa desde 1997, expresada en masivas ocupaciones de tierras (Lavanchy 1999, Klein 2008, Marimán 2012, Martínez 2012). Mientras, los intelectuales orgánicos de la sociedad mapuche construyen narrativa autonomista a partir de dichos conflictos, como lo muestran los casos de los think tank mapuches: Centro de Estudios y Documentos Mapuche Liwen en los 1990s, Comunidad de Historia Mapuche desde la segunda mitad del 2000. Y, recientemente, el Centro de Estudios Rümtun creado en el 2015, pero con antecedentes de actividad en años anteriores. Todos ellos propician poder regional plurinacional.

En el extenso territorio, entre el Bío Bío y el sur de Chiloé, se localizan más de 3.000 comunidades mapuche, mapuche-huilliche y mapuche-pehuenche. En su mayoría funcionan de modo tradicional o como comunidad indígena formada de acuerdo a la Ley Indígena $\mathrm{N}^{\mathrm{o}} 19.253$. Los programas y reivindicaciones de estas organizaciones coinciden en la recuperación de tierras, aunque algunas ponen distinto acento en el rescate de la identidad, la cultura y el desarrollo, así como en el reconocimiento constitucional de derechos por parte del Estado

${ }^{15}$ La región de La Araucanía está dividida administrativamente en dos provincias. Hacia su lado norte Malleco y hacia el sur Cautín.

Araucaria. Revista Iberoamericana de Filosofía, Política y Humanidades, año 17, $\mathrm{n}^{\circ} 34$. Segundo semestre de 2015. Pp. 279-301. ISSN 1575-6823 e-ISSN 2340-2199 doi: 10.12795/araucaria.2015.i34.13 
(Aylwin 2000). Otras reivindican el autogobierno-la autonomía y el cierre de relaciones con el Estado de Chile. Una de las organizaciones que ha incluido recientemente en su discurso la idea de la liberación nacional y la reconstrucción del pueblo-nación es la Coordinadora Arauco Malleco (CAM).

En las narrativas acerca del origen de la CAM se dice que nace oficialmente en 1998, pero comienza a gestarse en 1996, en un nguillatun ${ }^{16}$ realizado en la zona de Tranaquepe, cerca del Lago Lleu Lleu, Provincia de Arauco, donde se forma un primer germen de ella, como fue la Coordinadora Territoral Lafkenche (Klein 2008; Pairacán y Álvarez 2011; Weftun 2013), que contó con la suscripción de organizaciones y dirigentes como Adolfo Millabur (repetidas veces alcalde del pueblo de Titúa, actualmente en ejercicio del cargo), La Asociación Ñankucheo de Lumaco, dirigida por Galvarino y Adolfo Raiman, la ONG mapuche Xen Xen, Aukinco Domo, agrupación de mujeres mapuche, varias comunidades mapuche y dos organizaciones de mapuches urbanas de la ciudad de Santiago; Coordinadora Mapuche Metropolitana y Meli Wixan Mapu. Al segundo encuentro de Tranaquepe solo llegan comunidades en conflicto; las demás organizaciones, con excepción de las de Santiago, se marginan del encuentro, quizás por desacuerdo en planteamientos estratégicos y tácticos, en desavenencias políticas o en formas diferenciadas de solución a las demandas de tierras, especialmente respecto de cómo relacionarse con la institucionalidad indígena del Estado. Sintomático de la división es que de la Coordinadora Territorial Lafkenche sale la Identidad Territorial Lafkenche y la Coordinadora Mapuche de Comunidades en Conflicto Arauco Malleco. Cada una se lleva una parte del nombre de la organización embrionaria.

La Coordinadora de Comunidades Mapuches en Conflicto AraucoMalleco (CAM) irrumpió con acciones y también un imaginario polisémico, para algunos un poder unificado de la insurgencia mapuche, para otros sólo las comunidades en conflicto abierto por tierras con las forestales y latifundistas, y según expertos como Martín Correa, en un "archipiélago de muchas comunidades que se manifiestan en su autonomía, en un amplio territorio tradicional de la resistencia mapuche ${ }^{17}$ ". Un catastro de la Comisión Especial de Pueblos Indígenas (CEPI) realizado en 1994 detectó 80 conflictos de tierras en comunidades mapuches de la provincia de Malleco, muchos de los cuales no se expresaban orgánicamente o como demanda abierta, y los que se expresan generan inexorablemente hechos políticos. De hecho, en Arauco y Malleco

\footnotetext{
${ }^{16}$ Nguillatún es la ceremonia religiosa de los mapuches. Se realiza por cada comunidad o un conjunto de ellas, con una periodicidad que varía entre los dos a cuatro años o en caso de emergencia -un terremoto, por ejemplo- en forma no programada. La ceremonia puede durar varios días, en los que una comunidad o un conjunto de ellas conviven, hacen sacrificios, ofrendan, e intercambian alimentos. La machi o el machi es la/el líder espiritual a cargo de la rogativa, asistido por los lognkos de la o las comunidades participantes y dueñas de la ceremonia.

17 Entrevista Octubre 2013.
} 
existen 357 comunidades mapuche con Títulos de Merced $^{18}$, que suman una superficie de 90.601,34 hectáreas (González 1986). Estas comunidades representan el 12,2 del total de comunidades con Títulos de Merced, y en su mayoría presentan demandas de restitución de tierras.

Francisco Cortés (2013) distingue a la CAM de otras organizaciones por su estrategia y tácticas desplegadas en la consecución de sus objetivos, donde explicita la acción directa o resistencia con fines políticos. Estas operaciones, especialmente las acciones incendiarias contra las forestales, cambiarán el signo de las manifestaciones mapuche que se conocían hasta 1997, provocando expectación pública, una inédita respuesta política y represiva del Estado chileno, y el despliegue de violencias de diverso signo. Pairacán y Álvarez (2011) postulan linealmente, sin complejizar el contexto de la demanda de tierras y sin considerar la diversidad de expresiones que posee el movimiento mapuche, que la CAM viene a ocupar un vació reivindicativo y a dinamizar un proceso en que no existe conducción de organizaciones tradicionales, lo que parece dudoso a Cortés.

Lo que sí es evidente es el desplazamiento de organizaciones surgidas en dictadura, como la liderada por el ex militante comunista (y después socialista) José Santos Millao, llamada Ad-Mapu. Y el Consejo de Todas las Tierras que impulsó Aucán Huilcaman al inicio de la nueva democracia. Para Martínez (2012), dirigentes como Santos Millao, Camilo Quilamán, Isolde Reuque o Juan Huenupi entre otros, perdieron apoyo en las bases sociales. Incluso el más joven líder de la transición que fue Aucán Huilcamán, del Consejo de Todas las Tierras, y que desde un comienzo había denunciado estas alianzas - con los partidos de la Concertación por la Democracia, coalición gobernante- tampoco se salvó de estas críticas desde la CAM (varios militantes del CTT terminaron en partidos de gobierno: Domingo Colicoy, Eugenio Alcamán, Elisa Loncón, por ejemplo).

El gran enemigo de la CAM y las comunidades son las empresas forestales, fomentadas por el Estado desde el gobierno de Frei en los 1960s como una manera de mejorar tierras degradadas. En algunos centros de la reforma agraria bajo Frei y Allende se convocó a llevar a cabo asentamientos comunitarios, a hacerse parte del Plan de Desarrollo Forestal a través de Forestal Lebu, empresa del Estado, administrada por la Corporación de Fomento de la Producción CORFO (Cruz y Rivera 1984, Molina 2000). En Malleco y Cautín, durante el

18 Ya se ha explicado en la nota 8 que es un Título de Merced. Agregaremos ahora que el Estado Chileno otorgó 3.078 de estos títulos entre 1883-1927, en referencia a 475.423 hectáreas de la tierra que le permitió conservar de su otrora territorio a los mapuches. Estos títulos "beneficiaron" a 77.751 mapuches a un promedio de 6.1 hectáreas por persona (datos tomados de "Historia del Pueblo Mapuche" de José Bengoa). La usurpación de aproximadamente la mitad de esas tierras en la primera mitad del siglo XX, en un proceso de expansión del latifundio con el concurso de autoridades políticas, judiciales y policiales que lo permitieron (no protegieron a los indígenas), origina o está en la base del conflicto por recuperaciones de tierras mapuches en el presente.

Araucaria. Revista Iberoamericana de Filosofía, Política y Humanidades, año 17, $\mathrm{n}^{\circ}$ 34. Segundo semestre de 2015. Pp. 279-301. ISSN 1575-6823 e-ISSN 2340-2199 doi: 10.12795/araucaria.2015.i34.13 
Gobierno de Salvador Allende, se expropiaron 574 fundos con una superficie de 636.288,3 hectáreas. Todas estas comunidades mapuche tuvieron participación total o parcial en 138 predios, siendo la superficie favorable a los mapuches de 132.115,78 hectáreas físicas (Correa et al. 2002 y 2005).

Luego del golpe de Estado de 1973, la concentración de la tierra estará en grupos empresariales monopólicos que a través de sus empresas forestales llevaran adelante la expansión del monocultivo del pino insigne. Su principal soporte será el DL 701 de 1974, prácticamente fagocitado por estos grupos económicos, que les permitió tener un subsidio a las plantaciones por casi el $100 \%$, alcanzando para el pago de mano de obra y gozando del beneficio de no pago de contribuciones (Cavieres et al. 1986).

Como se explicó en la introducción, el año 1997 es clave en el nuevo ciclo de la insurgencia mapuche por recuperar territorio. Las comunidades Pichiloncoyan y Pililmapu se movilizan por recuperar el fundo Pidenco de la empresa forestal Mininco. En octubre en la comuna de Traiguén, otra comunidad autónoma, no adscrita a la CAM, la Antonio Ñirripil o Temulemu, dirigida por el lonko (líder) Pascual Pichún, detuvieron el paso de camiones forestales para recuperar el fundo Santa Rosa de Colpi de propiedad de una empresa forestal, la cual les tenía usurpadas 58,4 hectáreas del Título de Merced original. El predio fue entregado a los mapuche (Correa et al. 2005), pero después de 1973 llegó a manos de Forestal Mininco (Vergara et al. 1999).

El proceso de protestas y recuperación de tierras se dispara en el gobierno de Frei Ruiz Tagle (1994-2000). Hubo un máximo de 13 predios prácticamente ocupados en forma simultánea entre los días 22 y 27 de abril de 1999. Asimismo, las acciones violentas se convirtieron en una constante desde la quema de camiones de Forestal Arauco (en 1997), intensificándose notablemente en el último año. Entre el 1 de diciembre de 1997 y el 24 de mayo de 1999, se registraron un total de 17 acciones violentas, entre las que se cuentan ataques incendiarios a fundos y maquinarias forestales (ver mapa 2 evidenciando zonas de conflicto), enfrentamientos entre mapuches, carabineros y guardias forestales (Lavanchy 1999).

El ritmo de compra de tierras desde 1997 fue incrementándose, coincidiendo con el despliegue reivindicativo del movimiento mapuche y con las operaciones políticas del gobierno de turno, para controlar focos de activación política mapuche. Entre 1994 y 1997 el promedio de compra de tierras es de mil hectáreas anuales. En 1998 y 2002 las compras de tierras alcanzan las seis mil hectáreas promedio, y entre 2008 y 2011 el promedio anual supera las nueve mil hectáreas anuales (ver cuadro $\mathrm{n}^{\circ} 2$ ). Aunque no se conocen las cifras desglosadas de las tierras adquiridas, un porcentaje relevante de tierras recuperadas corresponderían aquellas de empresas forestales, especialmente Mininco y Forestal Arauco, recuperaciones en las que han participado 
organizaciones como Ad Mapu, Consejo de Todas las Tierras, Identidad Lakquenche, Asociación Ñancucheo de Lumako, organizaciones territoriales y comunidades mapuche autónomas, así como también comunidades adscritas a la CAM.

\section{Cuadro I. Hectáreas recuperadas a través del sistema de Compra Directa (art. 20 b) Ley 19253 a nivel nacional o en la Araucanía}

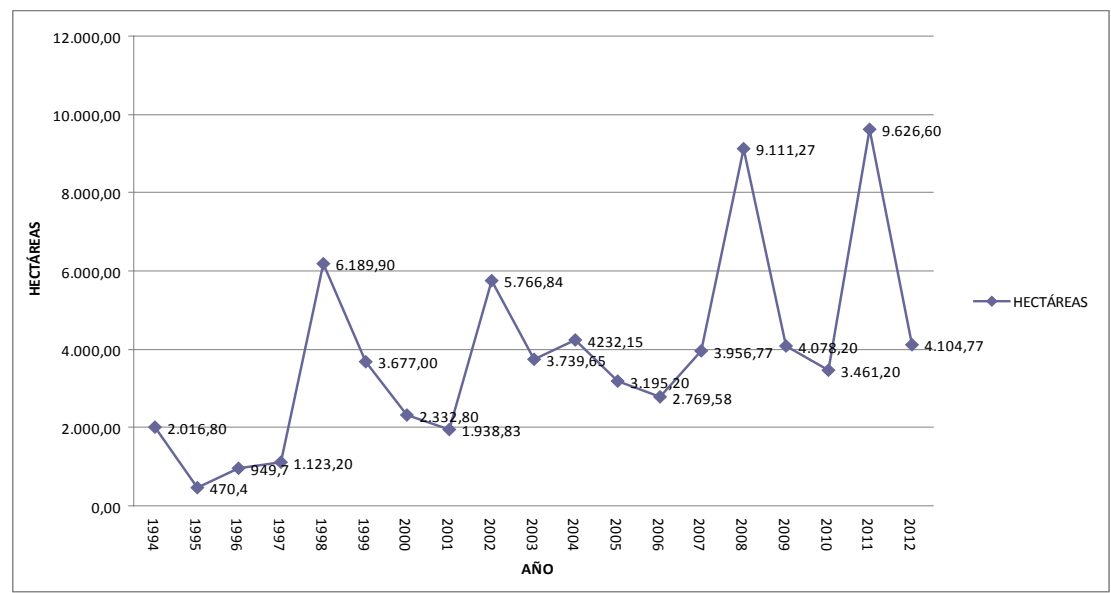

Fuente: Francisco Cortés. Elaborado en base a datos Fondo de Tierras y Aguas Indígenas CONADI (2013).

La ocupación de tierras de hecho es una estrategia mapuche transversal a las comunidades del territorio entre el Bío Bío y Chiloé (región de Los Lagos hacia el sur de la Araucanía). Sin embargo, contemporáneamente, en Tirúa, una de las zonas más aisladas de menor acceso de la provincia de Arauco, presenta las mismas condiciones de los territorios de comunidades pehuenches y huilliches de zonas cordilleranas de los Andes y de la Costa, que posibilitaron estas ocupaciones, aunque debieron resistir los primeros intentos de desalojo. En zonas que podríamos pensar más reguladas y relativamente centrales, cercanas a vías de comunicación o centros poblados, como es la provincia de Malleco, el despoblamiento ocurrido con la expansión forestal también ha hecho las zonas más inaccesibles y con menor presencia del control del Estado, que no sea a través de los puestos policiales y los vigilantes de los fundos de las empresas forestales.

En 2012, varias comunidades mapuche de las provincias de Arauco y Malleco, no adscritas a la CAM, habían iniciado "recuperaciones productivas" de tierras ancestrales. En la caleta de Quidico, costa de Arauco, Comuna de Tirua, 250 familias de la Comunidad Mapuche María Colipí, viuda de Maril, 
iniciaron un proceso de recuperación de tierras con fines productivos sobre el fundo Labranza de dos mil hectáreas de propiedad de Forestal Mininco. En el Fundo Rukañanco y La Posada de Contulmo, de 300 hectáreas y 200 hectáreas respectivamente, se hace la misma ocupación productiva. También se ocupan en Lleu Lleu 78 hectáreas. De igual modo se encontraban ocupados los Fundos “Cerro Negro" y Tirúa Sur, de 300 hectáreas, Fundo El Cardal de 1.600 hectáreas, y el Predio Choque de Forestal Mininco de 400 hectáreas.

Un año después, el 16 de abril de 2013, en la provincia de Malleco, las comunidades Andrés Huaiquiñir, Mateo Huenchuman, Pascual Pichulman, Juan Quilaqueo, Painen Marileo y Rain Chillacura, todas pertenecientes al Lof Cayu del Bajo Pellahuén, proceden a recuperar 15 mil hectáreas de tierras consideradas usurpadas por las empresas forestales Masisa, Mininco y Arauco. Sin embargo, estas comunidades no apelan a los argumentos de la CAM, sino que interpelan a la historia y los compromisos del Estado de Chile con el Pueblo Mapuche, al señalar que la recuperación de los predios se efectúa después de 132 años de usufructo de las tierras por personas naturales o jurídicas ajenas al pueblo mapuche. Señalan que en virtud del Convenio 169 de la OIT vigente en Chile desde 2009 es posible invocar el Tratado de Tapihue de 1825 que prohibió la presencia de chilenos en territorios mapuches, debidamente demarcados por el río Bío Bío. Justifican además las recuperaciones de tierras en el Artículo 28 de la Declaración de Naciones Unidas sobre los derechos de los Pueblos Indígenas, que establece el derecho a la reparación y restitución de tierras tradicionalmente ocupadas ${ }^{19}$.

El think tank Instituto Libertad y Desarrollo vinculado a la derecha chilena, contabilizó en quince años, de 1997 a 2012, más de mil acciones de violencia política mapuche en la Araucanía, cifra que causa alarma social y política, asociando a esta estadística el estancamiento de la inversión de capitales en la región, especialmente las provincias de Malleco y Arauco. Es decir, la causa del retraso y la pobreza de la región es el movimiento mapuche, argumento que a su manera es una nueva forma de prejuicio y discriminación promovida por el pensamiento neoliberal. El diario la Tercera relata que los mapuches han recuperado casi medio millón de hectáreas:

Cuando en 1994, el Estado chileno entregó el predio Los Tayos Bajos a la comunidad huilliche de Ampaniguén, en la localidad de Panguipulli, Región de Los Ríos, se dio por iniciado el llamado "proceso de restitución de tierras" a los pueblos originarios. A 20 años de aquel hito, las reivindicaciones indígenas, a lo largo del país, siguen siendo uno de los principales desafíos de cada gobierno frente a las etnias. Según cifras de la Corporación Nacional de Desarrollo Indígena (Conadi), entre 1994 y 2013, el Estado ha invertido \$ 275 mil millones en la compra de 187 mil hectáreas para ser entregadas a comunidades, lo que

${ }_{19}$ Mapuexpress 23 de abril de 2013.

Araucaria. Revista Iberoamericana de Filosofía, Política y Humanidades, año 17, n 34. Segundo semestre de 2015. Pp. 279-301. ISSN 1575-6823 e-ISSN 2340-2199 doi: 10.12795/araucaria.2015.i34.13 
ha beneficiado a 16 mil familias. Además, se han traspasado 278 mil hectáreas que eran propiedad fiscal, por lo que el total de tierras entregadas a los pueblos originarios asciende a 465 mil hectáreas ${ }^{20}$.

En cuanto a la inversión extranjera directa en la región de la Araucanía, según datos publicados en el Plan Araucanía (2010), se aprecia que de los 33.428 millones de dólares en 1990, consignados por el Comité de Inversión Extranjera, al inicio del régimen democrático de transición, las cifras comenzaron a descender rápidamente, pasando a 6.686 millones de dólares en 1991, a 13 millones de dólares en 2002, para desaparecer la inversión extranjera directa en el año 2004 hasta 2010 (Plan Araucanía 2010, 7). Estas cifras son congruentes con otras a nivel regional, que indican que en 2009 el PIB per cápita de la Araucanía fue el más bajo del país. Lo mismo ocurre desde 1990, mostrando un retraso de 20 años respecto del promedio nacional (Plan Araucanía 2010, 15), lo que estaría dando cuenta de un problema estructural, basado en la pobreza y en la marginalidad económica en que se encuentra el sector agrícola no exportador y, en especial, una pobreza provocada por la expansión forestal del pino insigne, que actúa como industria extractiva que no tributa en la región. La disminución y extinción de la inversión extranjera directa en la región puede atribuirse a múltiples factores, pero los sectores empresariales prefieren atribuirla a las acciones del movimiento mapuche. Según Lavanchy (1999), citando un diagnóstico de la Sociedad Nacional de Agricultura SNA, principal organización patronal en el agro, "las tomas de tierras y los ataques han alejado las inversiones tanto de los bancos como de los empresarios extranjeros... a ellos se suma una baja en el valor de los terrenos al estar en el centro de una zona de permanente conflicto. Por este motivo la SNA estima que hay millonarias pérdidas del patrimonio de sus afiliados del sur".

En cuanto a las tasas de expansión forestal estas descendieron a fines de los 1990s, pero luego se han mantenido a pesar de la conflictividad debido a las altas ganancias de la industria. Dirigentes le asignaron en 1999 al conflicto mapuche su descenso con el nuevo ciclo de ocupaciones mapuches de fundos forestales: "Las tasas de forestación que hasta 1994 promediaban las $77 \mathrm{mil}$ hectáreas anuales, bajaron en los últimos cinco años hasta 30 mil, que apenas se completarán este año 1999), según enfatizó el presidente de la Corporación de la Madera, José Ignacio Letamandi" (Revista del Campo No 1.213; op. cit Foester y Lavanchy, 1999).

Sin embargo, un estudio publicado por la Corporación Nacional Forestal CONAF (2009), señala que en la región de la Araucanía las plantaciones se incrementaron de 351.330 hectáreas (11\% de la superficie regional) en 1993, a

${ }^{20}$ El extracto fue recuperado del periódico La Tercera. Ver: http://www.mch.cl/2014/06/25/ historia-de-los-20-anos-de-traspasos-de-tierras-pueblos-indigenas/ 
572.184 hectáreas plantadas en 2007 (18\% de la superficie regional), incluyendo la "incendiaria" provincia de Malleco, epicentro de la rebelión mapuche. Los anunciados problemas económicos no se ajustan con los niveles de ganancias obtenidos por estas empresas, donde los principales grupos económicos forestales con plantas de celulosa, Arauco y Compañía Manufacturera de papeles y Cartones CMPC, entre 1996 y 2010 aumentaron sus ganancias en ocho veces, con rentabilidad superiores al 30\% (Frêne y Núñez 2010):

Las utilidades acumuladas durante el período 2000-2005 superaron los 2.268 millones de dólares. CMPC por su parte obtiene en 2005 utilidades mayores a 230 millones de dólares, acumulando en el período 2000-2005 más de 1.269 millones de dólares (Monsalve 2007). De igual modo, a pesar de la reivindicación de tierras del movimiento mapuche y de las acciones de violencia política atribuibles a la CAM, en el periodo 1993 a 2007, a juzgar por las declaraciones empresariales, se aprecia una disminución de la tasa de plantación, pero en ningún caso la paralización de las plantaciones ${ }^{21}$.

Lo indicado muestra la sostenibilidad de las empresas forestales y la expansión de las plantaciones a pesar de que el movimiento mapuche en Arauco y Malleco ha logrado que la CONADI compre a las empresas tierras para las comunidades en conflicto: "Las empresas, en general, han rehusado acceder a la demanda de restitución" (Aylwin et al. 2013), agudizando y alargando los conflictos, lo que se ve favorecido por la falta de mecanismo de expropiación. Estas tierras recuperadas constituyen un porcentaje reducido del patrimonio territorial de las empresas, que controlan un extenso latifundio forestal ${ }^{22}$. En 2009 las plantaciones en manos de las mega forestales alcanzaron en la región del Bío Bío - de la que forma parte la provincia de Arauco- una superficie plantada de 878.970 hectáreas (INFOR, 2009). La Comisión Presidencial para la Descentralización del año $2014^{23}$ propuso que las forestales pagaran tributos a los municipios, ya que la legislación chilena las exime de todo pago de impuesto predial o territorial por tala de bosques, concentrándose en las zonas forestales y mapuche la mayor pobreza del país con un $22 \%$ de la población versus el $15 \%$ promedio nacional ${ }^{24}$.

${ }^{21} \mathrm{Al}$ año 2003, de las 55 mil hectáreas plantas en la comuna de Lumaco, provincia de Malleco, un $55,7 \%$ pertenecen a pequeños y medianos propietarios y el $35,7 \%$ a empresas forestales (Montalba et al. 2005, 22).

22 Las empresas CMPC, su principal empresa en el sector forestal es Forestal Mininco, con un patrimonio forestal que supera las 700 mil hectáreas a 2010. Por su parte empresas Arauco, se forma por Bosques Arauco, Forestal Arauco, Forestal Cholguán, Forestal Celco, Forestal Alto Paraná. En Chile su patrimonio forestal supera el millón de hectáreas.

${ }^{23}$ Informe Comisión Presidencial para la Descentralización, octubre 2014.

${ }^{24}$ Las dos regiones con más pobres son Araucanía con el $(22.9 \%)$ y su vecina Bío Bío con el $(21,5 \% \%)$. Estudio Fundación Sol en base a cifras oficiales 2014 del Ministerio de Desarrollo Social. http://accionag.cl/noticias/pobreza-y-desigualdad-son-mas-fuertes-en-regiones-que-santiago/.

Araucaria. Revista Iberoamericana de Filosofía, Política y Humanidades, año 17, n 34. Segundo semestre de 2015. Pp. 279-301. ISSN 1575-6823 e-ISSN 2340-2199 doi: 10.12795/araucaria.2015.i34.13 


\section{La alternativa de una salida política: Región Plurinacional}

La política de atacar las consecuencias de los desastrosos planes de desarrollo forestal con criminalización y represión en vez de atender a las causas que han generado los odios, miedos, uso de la fuerza por ambos lados, no han hecho sino validar una hipótesis archiconocida en las ciencias sociales. A saber, que mientras más violencia se practique contra un grupo humano, que se plantea étnicamente diferente y es reconocido por el "otro" como tal, más se cohesiona y más se agudiza el conflicto. Y esos hechos de violencia y abuso-victimización son transmitidos a través de generaciones, ayudando a crear fronteras muchas veces infranqueables con malas disposiciones entre vecinos para el futuro.

El filósofo católico canadiense de Quebec, Charles Taylor, en su clásico libro sobre interculturalidad, sugiere su esencia en el respeto al otro sin miedo, aceptando que tenga poder específico:

El desafío es endémico a las democracias liberales porque están comprometidas, en principio, con la igual representación para todos. ¿Una democracia defrauda a sus ciudadanos, excluyendo o discriminando a algunos de ellos, de manera moralmente perturbadora, cuando las grandes instituciones no toman en cuenta nuestra identidad particular? ¿En qué sentido importa públicamente nuestra identidad como hombres y mujeres, como afroamericanos, asiáticoamericanos o aborígenes americanos, como cristianos, judíos o musulmanes? (2009) ${ }^{25}$.

Si "traducimos" a Taylor al tema mapuche - reconocer al otro y darle poder en su diversidad-, podemos conjeturar una región de La Araucanía ampliada, sumando zonas de Arauco, para pensar una región donde convivan pacíficamente mapuches y chilenos en toda su diversidad de origen (mestizos, alemanes, españoles, italianos, sirio-libaneses, entre otras), pero donde los mapuches tengan derechos y poder en la dirección de la misma. Lo que ha implementado Dinamarca en Groenlandia, con niveles altos de autonomía, es uno de muchos caminos a explorar y dialogar. Hay otros significativos en Canadá, Nueva Zelanda, en democracias avanzadas consociativas, como Bélgica, países donde se combate la ficticia homogeneidad represiva (la raza chilena) y se legisla sin miedo a los territorios y las etnias.

La violencia en la Araucanía tiene varios rostros, una violencia política social, usada de modo circunstancial por las comunidades mapuche y organizaciones como la CAM, que busca justicia y que se expresa como resistencia y respuesta legítima ante los otros tipos de violencia material y simbólica de tipo empresarial y del Estado de tipo permanente. En este sentido la violencia empresarial se expresa a través de las masivas plantaciones de

${ }^{25}$ Taylor, Charles. 2009: El Multiculturalismo y la Política del Reconocimiento. México: FCE. 
pino insigne y sus efectos medioambientales y territoriales, en cuanto tiene la posesión y tenencia de tierras ancestrales indígenas, sino también con la presencia de las guardias y grupos paramilitares para resguardo de sus predios y bosques, reivindicados por las comunidades mapuche.

Las recuperaciones de tierras en el período 1997 -2013 ha generado dos estrategias inéditas antes de 1990. Por una parte, la Ley Indígena introduce el mecanismo de compra de tierras en conflicto, en respuesta al movimiento mapuche que surge durante la dictadura, y que en Arauco y Malleco permite recuperar importantes superficies de tierras y resolver algunos conflictos históricos; y un segundo tipo corresponde a la ocupación de hecho, que se conoce como recuperaciones productivas, las que de acuerdo a la información de prensa superaría las 20 mil hectáreas en Arauco y Malleco. Las recuperaciones de tierras corresponden a la acción de comunidades autónomas, organizaciones mapuche tradicionales ( $A d M a p u$, Consejo de Todas Las Tierras) organizaciones $\mathrm{y}$ asociaciones indígenas locales, identidades y coordinadoras territoriales, todas ellas expresiones de la diversidad orgánica de la que se compone el movimiento mapuche en la Araucanía. Así lo señala uno de sus dirigentes:

Somos antisistémicos, porque no aceptamos la dominación occidental como modelo de vida y lo hacemos a través de la lucha territorial. Creemos que las vías que el sistema ofrece, sus programas y políticas sociales, resultan funcionales al sistema que nos oprime, no nos sirve. Queremos pasar a otro tipo de práctica: ocupar territorio y controlarlo. Mediante la acción directa quebrar de alguna manera la institucionalidad que se nos quiere imponer. Llamamos a este proceso "experiencias de control territorial, formas embrionarias de autonomía y liberación" (Llaitul y Arrate, 2012).

Este pensamiento puede cobrar sentido en muchas comunidades y organizaciones mapuches que ven como sus negociaciones y demandas ante el Estado no tiene respuesta o solución. Por ello, ¿puede un proyecto emancipador o de liberación nacional trascender hacia comunidades que no están en conflictos de tierras, que son una importante proporción? ¿El proyecto puede ir más allá de las provincias de Arauco y Malleco? ¿Si el planteamiento de la CAM no considera alianzas, es posible sumar las fuerzas y voluntad mayoritaria para su concreción? Son preguntas a las que solo el tiempo puede contestar. 


\title{
4. El futuro: Grupo minorizado o nación Indígena con poder en una macro región autónoma
}

\begin{abstract}
El mestizaje predominó al norte y al sur del Bío-Bío, al punto de que las fuentes históricas del siglo XVII señalan que sólo por excepción, en rincones muy apartados, quedaban indios puros. Desde entonces, y hasta el día de hoy, los llamados araucanos -eufemísticamente, mapuches- no son más que mestizos, aunque sean notorios los antiguos rasgos. Los propios araucanos formaron parte del aparato de dominación. Al hacerlo, recibían recompensas, beneficios y algunos honores; pero lo que más les atraía era disfrutar de las ventajas de la civilización material" (Extractos de "Araucanía: Errores Ancestrales", de Sergio Villalobos. El Mercurio de Santiago, 14 de mayo de 2000).
\end{abstract}

La filósofa Ángela Boitano (2014) deja al desnudo las tramas profundas de los discursos discriminadores y minorizantes sobre los mapuches que predominan en los diversos metarrelatos de las elites chilenas. Los "engaños" de ambos polos que reflexionan sobre lo mapuche: a.- los homogeneizadores, que buscan asimilar en un "nosotros" que niega al mapuche, entre los cuales el historiador Sergio Villalobos se ha convertido en un clásico; b.- los particularistas, que sin pretenderlo caen en la trampa del mero particularismo de la diferencia, que observa al mapuche como sobrevivencia identitaria, cultura folklorizada, ajena a la demanda de poder y otra visión de mundo que implica la lucha, el pensamiento y las prácticas sociales de este pueblo/nación.

La filósofa fustiga con ilustración y análisis tanto la homogenización como el multiculturalismo. Los mapuches, y cita los diálogos de Zizek con la corriente psicoanalista lacaniana, no quieren encerrarse en el sí mismo pero tampoco reducirse a la relación con el Gran Otro (el Estado chileno). Hay una cuestión relacional en tensión que hace difícil para el $w i n k a^{26}$ y el pensamiento universalista de los clásicos el comprender la realidad. Complementa los estudios históricos que rescatan la sobrevivencia de la nación y sus modos organizativos, que en español se califica como una suerte de federalismo comunitario (José Bengoa, los hermanos Marimán, Florencia Mallon, Stefan Lewis, Claudio Barrientos, Enrique Antileo, Pedro Cayuqueo, Martín Correa, entre otros). La filósofa explica las corrientes moralizantes sobre los mapuches -les hablan desde afuera y no les dan autonomía-, las que encierran puntos de vistas filosóficos e ideologías paternalistas-centralistas-nacionalistas homogeneizadoras, además de folklorizantes, negadoras y discriminantes.

El punto es complejo, porque todo lenguaje, incluyendo el de minoría, es esencialista y busca normalizar el vínculo con un sujeto subalterno. He aquí una novedad y un aporte indiscutible de la pensadora: el discurso de reconocer

${ }^{26}$ Winka o wingka es la palabra mapuche para designar al extranjero o el que no es mapuche. Es un estereotipo con un sentido peyorativo también, ya que incluye los significados de ladrón, estafador, persona desconfiable.

Araucaria. Revista Iberoamericana de Filosofía, Política y Humanidades, año 17, $\mathrm{n}^{\circ} 34$. Segundo semestre de 2015. Pp. 279-301. ISSN 1575-6823 e-ISSN 2340-2199 doi: 10.12795/araucaria.2015.i34.13 
a los mapuches derechos de minoría encierra trampas. No basta con criticar el peligro universalista que la igualdad aparente en el concepto de ciudadano de raíz liberal, como bien lo han advertido Fraser, Vattimo, Lyotard, Taylor, entre otros autores citados. El particularismo puede llevar a una forma de desprecio minorizante; por eso acuña el concepto de grupos minorizados. Lo sugiere con claridad: el discurso de la diferencia relegaría al mapuche a lo privado, lo raro, lo no-civilizado, el lugar donde no se puede legislar o cambiar la política.

La moral/ideología/política minorizante que nos sugiere la doctora, interpela los discursos de meras políticas, sin devolver poder, reconocer como sujeto colectivo y aceptar al otro como otro independiente de mí. Es decir, el discurso de dar planes y algunas tierras a una minoría lo niega como sujeto que puede ser "mayoría" o lo que quiera en su devenir. La violencia que viene de la pérdida de comunicación, como bien lo explica, no es sólo con el opresor explícito (el que usurpó tierras y ocupó sus territorios militarmente), también con aquellos arropados de una moral en apariencia "misericordiosa, compasiva, integradora", que construyen un sujeto foco de ayudas para reparar deudas y permitirle un mejor vivir como agricultor étnico o mapuche urbanizado, pero sin poder, sin autonomía, sin organización ni derecho alternativo, sin cosmovisión en mutación (el folklor estático). Estas miradas en el mundo del capitalismo globalizado con estados semi autoritarios como en América Latina, convierte a los grupos minorizados en sujetos condenados a la vergüenza, la humillación, el lamento.

A esta lógica minorizante, la "salida política" al conflicto que empodere a los mapuches con derechos ha sido la propuesta de una región autónoma plurinacional, que fue refrendada por la Comisión Presidencial para la Descentralización en el año 201427. Marimán y Valenzuela presentaron una propuesta de medidas al Área Social de los Jesuitas en Chile, quienes la entregaron a los candidatos presidenciales el año 2013. En síntesis se propuso en ambos documentos:

\section{La Elección de Intendentes y gobiernos regionales hacia un estado plurinacional}

La elección democrática de ejecutivos regionales -como todos los países de la OECD- favorece el poder de los que habitan los territorios, devuelve poder y facilita la pluralidad.

\section{Facilitar los partidos regionales y las plataformas de independientes}

Lo anterior, para que ofrezca oportunidades reales a los pueblos originarios de poder, implica que cada región debiera dictar su propia norma de elección de consejos regionales convertidos en parlamentos regionales, aceptando la

${ }^{27}$ La integraron dos co-autores de este artículo, esteban Valenzuela (Presidente) y José Marimán, ideólogo de la propuesta. Ver: http://www.senado.cl/prontus_senado/site/artic/20141007/ asocfile/20141007112343/descentralizacion_informe.pdf 
existencia de partidos regionales o plataformas ciudadanas independientes, hoy inexistentes ya que se exige tres regiones contiguas para ser partido y los independientes sólo pueden pactar al interior de pactos con partidos.

Así ocurre de Noruega (Lapones), Dinamarca (Inuit) a Guatemala (Comité Cívico de Sololá, por ejemplo).

3. Posibilidad de regiones crecidas, poderes provinciales y territorios especiales.

Permitir una descentralización democrática con pluralidad de formas, siguiendo la experiencia internacional que evita la homogeneidad:

Sumar territorios. Lo que puede ocurrir con municipios de mayoría mapuche de las provincias de Arauco, Bío-Bío (Alto) y Los Ríos con la actual Araucanía como Región Mapuche.

4. Región plurinacional con interculturalidad y poder mapuche: cuotas y autoridad ejecutiva asegurada.

El reconocimiento político explícito implica dar poder en la forma de región intercultural donde tiene asegurado parte del poder y de la autoridad representativa. Los dos instrumentos clásicos son:

a. Una autoridad ejecutiva representativa asegurada: se elige en padrón especial y es el representante mapuche, el presidente o co-presidente.

b. Un porcentaje del Consejo/Parlamento Regional por padrón especial (como ocurre en la región de Bruselas entre flamencos, valones y minoría alemana), o la existencia de un Consejo Integrado y otro Mapuche con potestades explícitas.

5. Ley de rentas regionales con fondo de Convergencia Regional que apoye a las regiones más vulnerables como la Araucanía (la más pobre en todos los indicadores).

\section{Gestión mapuche de los parques nacionales y zonas protegidas:}

Devolución como territorio mapuche de los parques nacionales del sur, para ser administrador por la autoridad mapuche con el apoyo técnico de CONAF, aceptando actividades económicas artesanales que implica incluir comunidades en un modelo sustentable

\section{Derechos políticos en lengua, cultura y justicia:}

Dar la autonomía a las regiones interculturales para crear universidad con misión étnica, enseñanza y uso masivo del lenguaje, creación de medios, fiestas y sistemas alternativos reconocidos en diversos ámbitos como la Justicia. El mapudungun está en declinación y la manera de revivirlo como en todas las luchas nacionales-étnicas, es contar con esta dimensión activa en una región que se declare plurinacional y plurilingüística.

\section{Epílogo:}

La violencia nació con la ocupación del Wallmapu y todo indica que no habrá paz en el sur del mundo hasta que no se restituyan tierras, autonomía, poder 
político y devolución económica relevantes a los mapuches. El negacionismo y la minorización van en retirada en Chile. Los mapuches han recobrado poder paralelo, autoestima, protagonismo de sus intelectuales, incluyendo el nombramiento de intendente Francisco Huechumillla ${ }^{28}$ en La Araucanía por la Presidenta Michelle Bachelet. Huenchumillaes un político mapuche centrista, quien visitó a las comunidades más conflictivas de Ercilla. El re-conocimiento va ocurriendo y se verá en los próximos años las nuevas dimensiones de la lucha por el autogobierno y la autonomía mapuche, y la capacidad de construir una coalición para ello desde el federalismo comunitario de la diversidad organizativa de los propios mapuches.

\section{Referencias bibliográficas:}

Aylwin, José. 2000. "Los conflictos en el territorio mapuche: antecedentes y perspectivas”. Revista perspectivas. Vol. 3, No 2, 277-300.

Aylwin, José, Nancy Yáñez y Rubén Sánchez. 2013. "Pueblo mapuche y recursos forestales en Chile: Devastación y conservación en contexto de globalización económica". Documento de trabajo IWGIA, Observatorio Ciudadano. Santiago Chile.

Bengoa, José. 1985. Historia del pueblo mapuche (siglos xix y xx). Santiago: Sur.

Barrientos, Claudio. 2014. Aproximaciones a la cuestión mapuche en Chile. Santiago: RIL.

Boitano, Ángela. 2014. Grupos minorizados: identidades politicas, tipos de reconocimiento y formas de ciudadanía. Tesis de doctora en filosofía. Chile: Pontificia Universidad Católica.

CAM Coordinadora Arauco Malleco. 1999. Extractos de Wallmapuche. Informe de Derechos Humanos.

Cavieres, A. G. Martner, R. Molina y V. Paile. 1986. "Especialización productiva, medioambiente y migraciones: el caso del sector forestal chileno". Agricultura y Sociedad $\mathrm{N}^{\circ} 4$.

\footnotetext{
${ }^{28}$ El primer intendente mapuche fue destituido por el gobierno de Bachelet en agosto del año 2015 en el contexto de los reclamos de camioneros y agricultores contra los sabotajes de mapuches, y tras el envío por parte del Intendente de un documento en que exponía las diversas formas de implementar la plurinacionalidad y el concepto de autodeterminación según el artículo 169 de la OIT. Fue reemplazado por el winka, Andrés Joannet, con el discurso de fortalecer el Estado de derecho y el orden. la destitución de Huenchumilla causó impacto y reforzó lo evidente: la ausencia de autonomía política en la Araucanía y de coalición territorial, sumando conciencia de la dominación centralista.
} 
Cayuqueo, Pedro. 2006. "Participación y voto mapuche en las municipales".

Contreras, Carlos. 2010. Los Tratados celebrados por los Mapuche con la Corona Española, la República de Chile y la República de Argentina. Berlín: Universitât de Berlín

Correa, Martín, Molina, Raúl y Yáñez, Nancy. 2005. La reforma agraria y las tierras mapuches: Chile 1962-1975. Santiago: LOM Ediciones.

Correa, Martín y Mella, Eduardo. 2010. Las razones del illkun/enojo: memoria, despojo y criminalización en el territorio mapuche de malleco. Santiago: LOM.

Correa, Martín, Molina, Rubén, y Yáñez, Nancy. 2002. "La reforma agraria y las tierras mapuches. América Latina". Revista del Doctorado en el Estudio de las Sociedades Latinoamericanas. Universidad ARCIS. Santiago, Chile.

Corporacion Nacional Forestal, Conaf. 2009. "Catastro de uso del suelo y vegetación, periodo 1993-2007”. Monitoreo y actualización Región de la Araucanía. Ministerio de Agricultura, Chile.

Díaz, José. 2011. El alma de la palabra, escritos inéditos del Padre Luis de Valdivia. Santiago: Pontificia Universidad Católica-Universidad Alberto Hurtado.

Dillehay, Tom. 1990. Araucanía, presente y pasado. Santiago de Chile: Editorial Andrés Bello.

Espinoza, Claudio y Mella, Magaly. 2013. "Dictadura militar y movimiento mapuche en Chile". Revista de Pensamiento Crítico Latinoamericano.

González, Héctor. 1986. "Propiedad comunitaria o individual: las leyes indígenas y el pueblo mapuche”. Revista Nutran. Año ii, №3. Santiago, Chile.

Klein, Fernando. 2008. "Los movimientos de resistencia indígena. El caso mapuche". Gazeta de Antropología N²4.

Lavanchy, Javier. 1999. "Conflicto y propuestas de autonomía mapuche”. Rehuefoundation.

Lavanchy, Javier. 1999a. "Perspectivas para la comprensión del conflicto mapuche". Rehuefoundation.

Leiva, Arturo. 1984. El primer avance a la araucanía: angol 1862. Temuco: Ediciones de la Universidad de la Frontera.

Lewis, Stephen. 1994. "Myth and the history of chile's araucanians". Radical History Review 58. Us.

Llaitul, Héctor y Arrate, Jorge. 2012. Weichan: conversaciones con un weychafe en la prisión política. Santiago: Ceibo Ediciones.

McFall, Sara. 2001. "Territorio mapuche y expansión forestal". Instituto de Estudios Indígenas. Universidad de la Frontera. Temuco Chile: Escaparate Ediciones. 
Mallon, Florencia. 1983. The defense of community in peru's central highlands: peasant struggle and capitalist transition, 1860-1940. Princeton: Princeton University Press.

Marimán, Pedro. 1990. "Algunas consideraciones en torno al voto mapuche". Temuco, Chile: Revista Liwen No2.

Marimán, José: 2012. Autodeterminación: Ideas políticas mapuche en el albor del siglo XXI. Santiago: LOM Ediciones.

Marimán, José 2014. "Movimiento mapuche 1990-2011. Disputando la representación política”. En Claudio Barrientos (ed.). Aproximaciones a la cuestión mapuche en Chile. Una mirada desde la historia y las ciencias sociales. Santiago, Chile: RIL Ediciones.

Molina, Raúl. 2000. "Comunidades mapuche y empresas forestales: tierras, bosques y conflictos”. En Pueblo mapuche, desarrollo y autogestión. Análisis $y$ perspectivas en una sociedad pluricultural. Centro Integral de Desarrollo Comunitario Casa de la Mujer Mapuche. Sociedad Mapuche Longo Kilapan. Instituto de Estudios Indígenas UFRO. Temuco Chile: Ediciones Escaparate.

Molina, Raúl. 2013. "Geografías mapuches: territorios, política y desafíos en tiempos de cambio”. Revista Geográfica del Sur. Volumen III, No1. Universidad de Concepción.

Montalba René, Carrasco, Noelia y Araya, José. 2005. "Contexto económico y social de las plantaciones forestales en Chile: El caso de la Comuna de Lumaco". Región de la Araucanía. Observatorio de Conflicto Ambientales $O L C A$. Santiago de Chile.

Naim, Moisés. 2014. El fin del poder. México: Debate.

Rivera, R. y M.E. Cruz. 1984. Pobladores rurales. Cambios en el poblamiento y el empleo rural en Chile. Grupo de Investigaciones Agrarias. Santiago de Chile: Academia de Humanismo Cristiano.

SNU Chile (2013). Memoria Programa de Pueblos Indígenas. Sistema de Naciones Unidas. Chile.

Valenzuela, Esteban. 1999. Alegato Histórico Regionalista. Santiago: Sur.

Valenzuela, Esteban. 2013. Utopistas Indianos en América. Buenos Aires: Ciudad Nueva.

Valdés, Marcos. 2007. "El comportamiento político mapuche". https:// www.google.clMarcos. +2007

Vergara Jorge, Aravena Andrea, Correa Martín, y Molina Raúl. 1999. "Las tierras de la ira". Praxis: Revista de Psicología y Ciencias Humanas, No 1. Santiago de Chile: Universidad Diego Portales.

Villalobos, Sergio. 2000, Mayo 14. "Araucanía: Errores ancestrales". Santiago, Chile: E1 Mercurio, A2. 
